\title{
Efficacy of renal replacement therapy in critically ill patients: a propensity analysis
}

Christophe Clec' $h^{1,2^{*}}$, Michaël Darmon ${ }^{3}$, Alexandre Lautrette ${ }^{4}$, Frank Chemouni ${ }^{1}$, Elie Azoulay ${ }^{2,5}$, Carole Schwebel $^{6}$, Anne-Sylvie Dumenil ${ }^{7}$, Maïté Garrouste-Orgeas ${ }^{2,8}$, Dany Goldgran-Toledano ${ }^{9}$, Yves Cohen $^{2}$ and Jean-François Timsit ${ }^{2,6}$

\begin{abstract}
Introduction: Although renal replacement therapy (RRT) is a common procedure in critically ill patients with acute kidney injury (AKI), its efficacy remains uncertain. Patients who receive RRT usually have higher mortality rates than those who do not. However, many differences exist in severity patterns between patients with and those without RRT and available results are further confounded by treatment selection bias since no consensus on indications for RRT has been reached so far. Our aim was to account for these biases to accurately assess RRT efficacy, with special attention to RRT timing.

Methods: We performed a propensity analysis using data of the French longitudinal prospective multicenter Outcomerea database. Two propensity scores for RRT were built to match patients who received RRT to controls who did not despite having a close probability of receiving the procedure. AKI was defined according to RIFLE criteria. The association between RRT and hospital mortality was examined through multivariate conditional logistic regression analyses to control for residual confounding. Sensitivity analyses were conducted to examine the impact of RRT timing.
\end{abstract}

Results: Among the 2846 study patients, 545 (19\%) received RRT. Crude mortality rates were higher in patients with than in those without RRT (38\% vs 17.5\%, P < 0.001). After matching and adjustment, RRT was not associated with a reduced hospital mortality. The two propensity models yielded concordant results.

Conclusions: In our study population, RRT failed to reduce hospital mortality. This result emphasizes the need for randomized studies comparing RRT to conservative management in selected ICU patients, with special focus on RRT timing.

\section{Introduction}

Acute kidney injury (AKI) significantly contributes to the morbidity and the mortality of critically ill patients through metabolic derangements, fluid overload and harmful effects of these disturbances on other failing organs. Renal replacement therapy (RRT), although not achieving the same level of homeostasis as a normally functioning kidney, helps limit the consequences of AKI and allows adequate administration of fluids and nutritional support. However, its benefits (aside from lifethreatening complications, such as severe hyperkalemia,

\footnotetext{
* Correspondence: christophe.clech@avc.aphp.fr

'Medical-surgical ICU, Avicenne Teaching Hospital, 125 route de Stalingrad, Bobigny, 93000, France

Full list of author information is available at the end of the article
}

pulmonary edema, and intractable acidosis) in critically ill patients with AKI remain unclear.

Available data are derived from uncontrolled studies, which all showed higher mortality rates among populations treated with RRT [1-5]. Due to their design, however, confounders and biases may have limited their accuracy. Particularly, treatment selection bias [6] may have confounded the results. This kind of bias occurs when no agreed-upon indications exist for a given treatment or procedure, which is the case for RRT despite the recent publication of recommendations for the prevention and management of AKI in the intensive care unit (ICU) [7]. Since there are no clear guidelines about whether and when RRT should be started, patients' characteristics, in-ICU events, and other aspects of ICU 
care, which may also affect outcomes, may confound the analysis of RRT efficacy, leading to inconclusive results. The propensity score technique described by Rosenbaum and Rubin is a powerful method to control for treatment selection bias $[8,9]$. The aim of this study was to use the propensity technique to estimate the association of RRT with in-hospital mortality in ICU patients with AKI.

\section{Materials and methods}

\section{Study design and data source}

We conducted an observational study in a multiple-center database (OUTCOMEREA) from January 1997 to June 2009. Methods of data collection and quality of the database have been described in details elsewhere [10]. Briefly, a large set of data on a random sample of patients older than 16 years with ICU stays longer than $24 \mathrm{~h}$ was prospectively collected by the senior physicians of the participating ICUs and entered into the database each year. The quality control procedure involved multiple automatic checking of internal consistency and biennial audits.

\section{Ethics approval}

In accordance with French law, the OUTCOMEREA database was declared to the Commission Nationale de l'Informatique et des Libertés. The study was approved by the ethics committee of Clermont-Ferrand, France. Since the study did not modify patients' management and data were processed anonymously, the need for informed consent was waived.

\section{Study population and definitions}

All patients in the database were eligible. Exclusion criteria were: chronic kidney disease (CKD) (with or without complete loss of kidney function), pre-renal cause of renal dysfunction (that is rapidly reversible functional renal failure), multiple ICU stays, decision to withhold or withdraw life-sustaining treatments, and renal replacement therapy for extra-renal indications (such as, intoxications or cardiogenic shock). CKD was defined either according to the Acute Physiology and Chronic Health Evaluation (APACHE) II definition or a specific code in the database when not requiring dialysis. Prerenal cause of renal dysfunction was also identified through a specific code in the database. The reason for excluding these patients was that their prognosis may be different from that of patients with prior normal renal function who present a non-rapidly reversible cause of AKI. Patients with multiple ICU stays, or with a decision to withhold or withdraw life-sustaining treatments, were also excluded to avoid confusion in the assessment of hospital mortality.

Among the remaining patients, those in whom AKI occurred were analyzed. AKI was defined according to the RIFLE (Risk, Injury, Failure, Loss and End-stage renal failure) criteria [11], and patients were classified according to the maximum RIFLE class (Risk, Injury or Failure) reached during their ICU stay. The maximum RIFLE class was determined before RRT initiation in patients who received RRT and whenever during the ICU stay in patients who did not. Since the 6- and 12-h urine outputs were not recorded in the database, we used the glomerular filtration rate (GFR) only. The GFR criteria were determined according to changes in serum creatinine from baseline values. As AKI may be present on ICU admission in a high proportion of patients, we chose to assess baseline creatinine values using the Modification of Diet in Renal Disease (MDRD) equation. As recommended by the Acute Dialysis Quality Initiative Group, a normal GFR of $75 \mathrm{ml} / \mathrm{min} / 1.73 \mathrm{~m}^{2}$ before ICU admission was assumed [11].

RRT consisted of intermittent hemodialysis or continuous veno-venous hemofiltration/hemodiafiltration. All participating centers were able to provide both techniques of RRT. The decision to start RRT was left at the discretion of the attending ICU physicians.

\section{Data collection}

The following data were recorded:

- baseline characteristics on ICU admission: age, sex, McCabe class (class 1, no fatal underlying disease; class 2 , underlying disease fatal within five years; class 3 , underlying disease fatal within one year), Simplified Acute Physiology Score (SAPS) II, comorbidities assessed according to the APACHE II definitions, transfer from ward (defined as a stay in an acute-bed ward $\geq 24$ hrs immediately before ICU admission), and admission category (medical, scheduled surgery, or unscheduled surgery),

- during the ICU stay: daily biological parameters (blood urea nitrogen, serum creatinine, kaliemia), daily urine output, daily weight, time from admission to maximum RIFLE class, time to RRT, daily Sequential Organ Failure Assessment (SOFA) score, and modified SOFA score (mSOFA, SOFA - specific renal component),

- on ICU discharge: renal status (recovery or need for prolonged renal support), and length of ICU stay, and,

- on hospital discharge: vital status.

\section{Endpoints}

The primary endpoint was hospital mortality.

The secondary endpoints were the length of ICU stay, and renal status on ICU discharge.

\section{Propensity technique}

Since RRT was not randomly assigned in our study population, treatment selection bias was accounted for by using the propensity technique. When building a 
propensity score, the main risk is the omission of an important variable in the propensity regression. Thus, we fitted and compared two different models to strengthen our analysis. As recommended, propensity scores were determined through multivariate logistic regression [12], in which RRT was the dependent variable. Independent variables were related to the probability of receiving the treatment and also outcome in order to reduce both the bias and the variance in the estimation of treatment effect $[13,14]$. Independent variables introduced in model 1 were: rising creatinine reflected by maximum RIFLE class, oliguria reflected by the 24-h urine output on reaching maximum RIFLE class, and SAPS II score. Independent variables introduced in model 2 were: blood urea nitrogen, serum creatinine and kaliemia measured on reaching maximum RIFLE class (that is, before RRT was started), fluid accumulation (reflected by the difference between patients' weight recorded on reaching maximum RIFLE class and that recorded on ICU admission), and SAPS II score.

Using an algorithm [15], we matched patients who received RRT during their ICU stay to other AKI patients who did not on the basis of each of the two propensity scores that we built (model 1 and model 2). Specifically, we sought to match each patient with RRT up to three controls who had the closest propensity score (within 0.05 on a scale of 0 to 1 ).

Besides, patients were also matched on center and period of admission to account for possible inconsistent institutional practices or changes in RRT practices over time. Age (+/ 5 years) was the final matching criterion. The adequacy of the propensity scores in controlling for treatment selection bias was demonstrated by testing for differences between matched patients in biological parameters likely to trigger RRT on reaching maximum RIFLE class.

The goodness of fit and the discrimination of the two logistic regression models used to derive a propensity score for RRT were evaluated by the Hosmer-Lemeshow (HL) test, and the c statistic (area under the receiver operating characteristics curve), respectively.

\section{Statistical analyses}

Results are expressed as numerical values and percentages for categorical variables, and as means and standard deviations (SD) or medians and quartiles [Q1-Q3] for continuous variables.

In the whole cohort, comparisons of patients with and those without RRT were based on chi-square tests for categorical data, and on Student's t-test or Wilcoxon's test for continuous data, as appropriate.

Comparisons between matched patients were based on univariate conditional logistic regression. Multivariate conditional logistic regression analysis was used to examine the association between RRT and subsequent hospital mortality, adjusting for variables potentially related to mortality that were not considered in the propensity regression (namely baseline characteristics that had a $P$ value $<0.1$ in univariate analysis, and the modified SOFA score (SOFA score - specific renal component) computed on the day maximum RIFLE class was reached).

Sensitivity analyses were performed to test whether any delay in RRT initiation could affect patients' prognosis. For that purpose, the timing of RRT was divided into three classes (less than $24 \mathrm{~h}$, between 24 and $48 \mathrm{~h}$, greater than $48 \mathrm{~h}$ after reaching maximum RIFLE class).

Since the use of the MDRD equation to estimate baseline creatinine values has not been validated in ICU patients, we also performed sensitivity analyses that included only patients with a normal serum creatinine value measured on ICU admission.

Wald $\chi 2$ tests were used to determine the significance of each variable. Adjusted odds ratios (ORs) and 95\% confidence intervals (CIs) were calculated for each parameter estimate.

Analyses were computed using the SAS 9.1 software package (SAS Institute, Cary, NC, USA).

\section{Results}

\section{Study patients}

Over the study period, 10,911 patients with a single ICU stay were screened, of whom 2,272 were excluded for the following reasons: decision to withhold or withdraw life-sustaining treatments $(n=1,378,12.6 \%)$, history of chronic kidney disease $(n=672,6.2 \%)$, functional renal failure $(n=176,1.6 \%)$, and RRT for extra-renal indications $(n=46,0.4 \%)$.

Among the remaining 8,639 patients, 2,846 (32.9\%) had AKI (1,025 (36\%) R class patients, 830 (29.2\%) I class patients, and 991 (34.8\%) F class patients).

RRT was initiated in 545 (19.1\%) AKI patients (41 (7.5\%) R class patients, 110 (20.2\%) I class patients, and 394 (72.3\%) F class patients).

Patients who received RRT were younger, had higher severity scores, were more likely to be transferred from ward, and presented more comorbidities than patients who did not receive RRT (Table 1). Differences between patients with and without RRT according to the maximum RIFLE class reached during the ICU stay are shown in Additional files 1, 2, and 3.

\section{Dynamics of AKI and timing of renal replacement therapy} AKI occurred early in the course of ICU stay. Threequarters of the patients reached their maximum RIFLE within three days after ICU admission.

When a decision of RRT was made, RRT was started less than $48 \mathrm{~h}$ after reaching maximum RIFLE class in 
Table 1 Baseline characteristics of acute kidney injury (AKI) patients with and without renal replacement therapy (RRT).

\begin{tabular}{|c|c|c|c|}
\hline Variable & $\begin{array}{l}\text { Patients with RRT } \\
(N=545)\end{array}$ & $\begin{array}{l}\text { Patients without RRT } \\
(N=2301)\end{array}$ & $P$ value \\
\hline Age, mean (SD) & $61.3(16.6)$ & $67.6(15.5)$ & $<0.0001$ \\
\hline Males, no. (\%) & $363(66.6)$ & 1309 (59.9) & $<0.0001$ \\
\hline SAPS II score, mean (SD) & $56.8(19.2)$ & $48.6(19.8)$ & $<0.0001$ \\
\hline APACHE II score, mean (SD) & $21.4(7.0)$ & $19.6(7.1)$ & $<0.0001$ \\
\hline Transfer from ward, no. (\%) & $291(53.4)$ & $1072(46.6)$ & 0.004 \\
\hline \multicolumn{4}{|l|}{ McCabe, no. (\%) } \\
\hline 1 & $314(57.6)$ & $1352(58.8)$ & \\
\hline 2 & $188(34.5)$ & $771(33.5)$ & 0.88 \\
\hline 3 & $43(7.9)$ & $178(7.7)$ & \\
\hline \multicolumn{4}{|l|}{ Admission category, no. (\%) } \\
\hline Medical & $388(71.2)$ & 1655 (71.9) & \\
\hline Scheduled surgery & $52(9.5)$ & $259(11.3)$ & 0.25 \\
\hline Unscheduled surgery & $105(19.3)$ & $387(16.8)$ & \\
\hline \multicolumn{4}{|l|}{ Chronic coexisting conditions, no. (\%) } \\
\hline Cardiac disease & $89(16.3)$ & $420(18.3)$ & 0.29 \\
\hline Respiratory disease & $55(10.1)$ & $311(13.5)$ & 0.03 \\
\hline Liver disease & $50(9.2)$ & $128(5.6)$ & 0.002 \\
\hline Immunodeficiency & $104(19.1)$ & $336(14.6)$ & 0.01 \\
\hline Uncomplicated diabetes mellitus & $63(11.6)$ & $257(11.2)$ & 0.79 \\
\hline Complicated diabetes mellitus & $30(5.5)$ & $118(5.1)$ & 0.72 \\
\hline
\end{tabular}

SAPS, Simplified Acute Physiology Score; APACHE, Acute Physiology and Chronic Health Evaluation.

479/545 (87.9\%) patients. Continuous veno-venous hemofiltration/hemodiafiltration and intermittent hemodialysis were used as initial RRT modality in 345 (63.3\%) patients and 200 (36.7\%) patients, respectively.

Details on timings of AKI and RRT for each RIFLE class are shown in Tables 2 and 3.

Differences in parameters (measured on reaching maximum RIFLE class) likely to trigger RRT between patients who actually received RRT and those who did not are presented in Table 4. Patients with RRT had higher blood urea nitrogen, serum creatinine and kaliemia but their $\mathrm{pH}$ values were not significantly lower.

\section{Matching on the propensity scores}

The two propensity models showed satisfying goodness of fit and discrimination ( $P$ values for the HL test: 0.39 and 0.52, c statistics: 0.80 and 0.78 , in models 1 and 2, respectively). The percentage of matched patients was

Table 2 Timing of acute kidney injury (AKI).

\begin{tabular}{lcccc}
\hline & $\begin{array}{c}\text { All } \\
\text { patients }\end{array}$ & $\begin{array}{c}\text { R class } \\
\text { patients }\end{array}$ & $\begin{array}{c}\text { I class } \\
\text { patients }\end{array}$ & $\begin{array}{c}\mathbf{F} \text { class } \\
\text { patients }\end{array}$ \\
\hline Time to AKl onset & $2[1-2]$ & $1[1-2]$ & $2[1-2]$ & $1[1-2]$ \\
$\begin{array}{l}\text { Time to maximum RIFLE } \\
\text { class* }\end{array}$ & $2[1-3]$ & $1[1-2]$ & $2[1-3]$ & $2[1-3]$ \\
\hline pen $^{*}$ & & & &
\end{tabular}

Results are expressed as medians (in days) and [interquartile range]. *From ICU admission (day 0). high despite numerous and strict matching criteria. In model 1, 383/545 (70\%) patients who received RRT could be matched to 726 controls who did not receive RRT. In model 2, 376/545 (69\%) RRT patients could be matched to 754 controls. In both models, there were no differences between patients with and those without RRT in biological parameters likely to trigger RRT on reaching maximum RIFLE class (Table 5), thus confirming the ability of the propensity scores to control for treatment selection bias. However, there remained differences in SAPS II, mSOFA, urine output and fluid accumulation that were thus adjusted for (Table 5).

Impact of renal replacement therapy

RRT resulted in longer lengths of ICU stay after reaching maximum RIFLE class (see Additional files 4 and 5) but did not reduce mortality. Crude hospital mortality rates of patients with and without RRT were $45.1 \%$ and

Table 3 Timing of renal replacement therapy initiation.

\begin{tabular}{lcccc}
\hline & $\begin{array}{c}\text { All } \\
\text { patients }\end{array}$ & $\begin{array}{c}\text { R class } \\
\text { patients }\end{array}$ & $\begin{array}{c}\text { I class } \\
\text { patients }\end{array}$ & $\begin{array}{c}\text { F class } \\
\text { patients }\end{array}$ \\
\hline Time from AKl onset & $1[0-3]$ & $0[0-1]$ & $1[0-2]$ & $1[0-3]$ \\
Time from maximum RIFLE & $0[0-1]$ & $0[0-1]$ & $0[0-1]$ & $0[0-1]$ \\
class & & & &
\end{tabular}

Results are expressed as medians (in days) and [interquartile range]. AKI, acute kidney injury. 
Table 4 Differences in parameters likely to trigger renal replacement therapy (RRT) on reaching maximum RIFLE class between patients with and without RRT (whole cohort).

\begin{tabular}{lccc}
\hline & $\begin{array}{c}\text { Patients with } \\
\text { RRT }\end{array}$ & $\begin{array}{c}\text { Patients without } \\
\text { RRT }\end{array}$ & $\boldsymbol{P}$ value \\
& $\boldsymbol{N}=\mathbf{5 4 5}$ & $\boldsymbol{N}=\mathbf{2 3 0 1}$ & \\
\hline Urea $(\mathrm{mmol} / \mathrm{L})$ & $20[14-28]$ & $14[10-20]$ & $<0.001$ \\
Creatinine $(\mathrm{mmol} / \mathrm{L})$ & $305[231-408]$ & $178[143-247]$ & $<0.001$ \\
Potassium $(\mathrm{mmol} / \mathrm{L})$ & $4.3[3.8-5.1]$ & $4.2[3.7-4.7]$ & $<0.001$ \\
pH & $7.34[7.24-7.43]$ & $7.36[7.27-7.44]$ & 0.4 \\
mSOFA & $7[4-10]$ & $5[2-7]$ & $<0.001$ \\
SAPS II & $49[38-62]$ & $41[32-53]$ & $<0.001$ \\
Urine output $(\mathrm{L})$ & $0.4[0.1-1.1]$ & $1.3[0.6-2.3]$ & $<0.001$ \\
Fluid accumulation & $4[2-8]$ & $2[0-4]$ & $<0.001$ \\
(L) & & &
\end{tabular}

Results are expressed as medians and [interquartile range]. SOFA, Sequential Organ Failure Assessment; mSOFA, SOFA - specific renal component; SAPS, Simplified Acute Physiology Score.

$23.4 \%$, respectively $(P<0.001)$. Among patients who received RRT, 92 of the 338 survivors (27.2\%) still needed renal support on ICU discharge.

After matching on the propensity scores, patients who received RRT still had higher mortality rates than their respective controls (model 1: $38.9 \%$ vs $22.2 \%, P<0.001$;

Table 5 Differences in parameters likely to trigger renal replacement therapy (RRT) on reaching maximum RIFLE class between patients with and without RRT (matched patients).

\begin{tabular}{lccc}
\hline & $\begin{array}{c}\text { Patients with } \\
\text { RRT }\end{array}$ & $\begin{array}{c}\text { Patients without } \\
\text { RRT }\end{array}$ & P value \\
\hline Model 1 & $N=383$ & $N=726$ & \\
Urea (mmol/L) & $15[10-23]$ & $15[11-24]$ & 0.3 \\
Creatinine (mmol/L) & $217[158-281]$ & $214[158-271]$ & 0.4 \\
Potassium (mmol/L) & $4.1[3.6-4.7]$ & $4.1[3.6-4.6]$ & 0.9 \\
pH & $7.34[7.24-7.44]$ & $7.36[7.28-7.44]$ & 0.5 \\
mSOFA & $7[5-9]$ & $5[3-8]$ & $<0.001$ \\
SAPS II & $50[38-62]$ & $43[34-56]$ & $<0.01$ \\
Urine output (L) & $0.6[0.2-1.3]$ & $1.4[0.7-2.5]$ & $<0.001$ \\
Fluid accumulation & $4[2-8]$ & $2[0-6]$ & $<0.01$ \\
(L) & & & \\
Model 2 & $N=376$ & $N=754$ & \\
Urea (mmol/L) & $16[10-23]$ & $14[10-22]$ & 0.9 \\
Creatinine (mmol/L) & $217[158-286]$ & $203[144-265]$ & 0.12 \\
Potassium (mmol/L) & $4.1[3.6-4.8]$ & $4.1[3.6-4.6]$ & 0.4 \\
pH & $7.33[7.24-7.43]$ & $7.36[7.27-7.45]$ & 0.3 \\
mSOFA & $7[5-10]$ & $5[3-8]$ & $<0.001$ \\
SAPS II & $50[39-63]$ & $42[34-54]$ & $<0.001$ \\
Urine output (L) & $0.6[0.2-1.2]$ & $1.2[0.5-2.2]$ & $<0.001$ \\
Fluid accumulation & $4[2-8]$ & $2[1-6]$ & $<0.03$ \\
(L) & & & \\
\hline Results a expressed & & & \\
\hline
\end{tabular}

Results are expressed as medians and [interquartile range]. SOFA, Sequential Organ Failure Assessment; mSOFA, SOFA - specific renal component; SAPS, Simplified Acute Physiology Score. model $2: 38 \%$ vs $18.3 \%, P<0.001$ ), in univariate analysis. After adjustment on confounding variables, RRT was not associated with a reduced hospital mortality, whatever its timing (Table 6). Additional files 6 and 7 show details according to the maximum RIFLE class reached during the ICU stay.

The sensitivity analyses that included only patients with a normal serum creatinine value measured on ICU admission yielded similar results as the full analysis (Additional file 8).

\section{Discussion}

While the impact of RRT modalities has been widely investigated through randomized controlled trials [16-21], the overall efficacy of RRT remains uncertain. Actually, there is no real head-to-head comparison of AKI patients with and without RRT in the current literature. Mortality rates are usually higher in patients with than in those without RRT [1-5]. However, no definitive conclusions can be can be drawn from these data due to the absence of clear indications for RRT and the many differences in severity patterns between patients who receive RRT and those who do not. In other words, treatment selection bias and patients' underlying severity are major confounders making the assessment of RRT efficacy challenging.

Our study brings a new insight in the field. By using the propensity technique, we were able to compare hospital mortality rates in matched patients with and without RRT, having a close probability of receiving RRT (somewhat as though RRT had been 'randomly assigned'). Moreover, since the SAPS II score was included in the propensity regressions, matched patients with and without RRT had also a similar predicted

Table 6 Association of renal replacement therapy (RRT) with hospital mortality in multivariate conditional logistic regression (matched patients) according to timing of RRT.

\begin{tabular}{|c|c|c|c|}
\hline & OR & $95 \% \mathrm{Cl}$ & $P$ value \\
\hline \multicolumn{4}{|l|}{ Model 1} \\
\hline All RRT (whatever the timing) & 1.30 & $0.96-1.78$ & 0.09 \\
\hline Immediate RRT* & 1.43 & $0.91-2.22$ & 0.12 \\
\hline Early RRT** & 0.99 & $0.45-2.15$ & 0.92 \\
\hline Delayed RRT*** & 2.37 & $1.04-5.40$ & 0.04 \\
\hline Model 2 & & & - \\
\hline All RRT (whatever the timing) & 1.41 & $1.02-1.94$ & 0.04 \\
\hline Immediate RRT* & 1.14 & $0.71-1.81$ & 0.59 \\
\hline Early RRT** & 2.31 & $0.96-5.67$ & 0.06 \\
\hline Delayed RRT ${ }^{* * *}$ & 2.29 & $1.05-4.99$ & 0.04 \\
\hline
\end{tabular}

$\mathrm{OR}$, odds ratio; $\mathrm{Cl}$, confidence interval. *Initiated within $24 \mathrm{~h}$ after reaching maximum RIFLE class; ${ }^{*}$ initiated between 24 and $48 \mathrm{~h}$ after reaching maximum RIFLE class; ${ }^{* *}$ initiated more than $48 \mathrm{~h}$ after reaching maximum RIFLE class. 
hospital mortality. Consequently, the risk of biased assessment of the association between RRT and hospital mortality was minimized.

Like in the interesting study of Elseviers et al. [22] that reported an increased risk of death for RRT compared to conservative treatment in ICU patients after extensive adjustment on disease severity, we failed to demonstrate any beneficial effect of RRT. While it cannot be totally run out that RRT per se is potentially harmful (hemodynamic instability, central venous catheter-related blood stream infections, inflammation and coagulation disorders, which are common complications of RRT, may well have outweighed its metabolic benefits), these results emphasize the need for a critical reappraisal of current RRT practices and definitions of AKI. Particularly, it must be kept in mind that timing of RRT initiation is undoubtedly a key issue. In this regard, a plausible explanation for our findings is that RRT was in fact initiated too late. Actually, patients were classified according to the glomerular filtration rate (GFR) criteria of RIFLE whereas increases in serum creatinine often lag behind the true reduction in GFR. Thus, although RRT was in place within $24 \mathrm{~h}$ after reaching maximum RIFLE class in the vast majority of patients, it might well have been initiated at a more advanced stage of renal dysfunction than clinically appreciated. So, our results do not imply, as one may believe at first sight, that RRT should be abandoned. Rather, the key message could be: 'initiate RRT as early as possible'. That patients who received RRT had more coexisting organ failures on reaching maximum RIFLE class than their matched controls lends support to this hypothesis of delayed AKI diagnosis and RRT. Since initiation of RRT when multiple organ failures are present probably limits its ability to improve patients' outcomes, the utilization of highly sensitive and early diagnostic biomarkers such as cystatin $\mathrm{C}$ or neutrophil gelatinase-associated lipocalin (instead of serum creatinine) as triggers for RRT is worth considering for future investigations in the ICU [23-30].

Despite the use of an original statistical approach minimizing the risk of bias, our study has potential limitations that merit consideration.

First, residual confounding cannot be totally excluded because of the observational design. However, by applying the propensity technique and matching on age, and center and period of admission, we dealt with confounding more extensively than in prior reports. Besides, that the two propensity models yielded similar results made the hypothesis of having omitted an important confounding variable unlikely.

Second, we encountered the same problem as others [31,32]: the 6- and 12-h urine outputs were not recorded in our database. Therefore, patients were classified according to the GFR criteria only. Patients classified according the GFR criteria seem to be more severely ill and have slightly higher mortality rates than their counterparts classified according to the urine output criteria [33,34]. Having considered both criteria may have resulted in a different estimation of RRT efficacy. Yet, urine output does not differentiate functional (prerenal) AKI from organic AKI and new serum or urine biomarkers are probably much more reliable for the early diagnosis of AKI.

Third, the MDRD equation used to estimate baseline creatinine values has not been validated in ICU patients. Nevertheless, the sensitivity analysis including only data from patients with a normal serum creatinine value on ICU admission yielded similar results as the full analysis, showing that the use of the MDRD equation did not bias the results.

Fourth, the use of the MDRD equation to estimate baseline creatinine values refrains from precisely establishing AKI onset (that is, patients with an apparent early-onset AKI may in fact have developed AKI for several days before ICU admission). This could be problematic in that the prognosis of early AKI may differ from that of late AKI. That results of the sensitivity analysis, including only data from patients with a normal serum creatinine value on ICU admission, yielded similar results as the full analysis runs counter to the hypothesis of differential prognosis and impact of RRT between early and late AKI. However, this issue needs further evaluation.

Fifth, it might be argued that RRT initiation may have prevented $\mathrm{R}$ or I class patients from reaching a higher RIFLE class (thus leading to an underestimation of their degree of renal dysfunction, and subsequent comparison of RRT patients with non-RRT patients having a more severe renal dysfunction). Yet, this limit, which is inherent to the RIFLE classification, does not apply to F class patients. Since odds ratios of mortality associated with RRT in the whole population were similar as those in the F class patients, it is very unlikely that results were flawed by a potential misclassification bias induced by an underestimation of renal dysfunction in RRT patients.

Sixth, the prognostic impact of the dose and initial modality of RRT was not assessed. It must be emphasized, however, that all randomized controlled trials conducted so far have showed equivalence between high and low doses, and continuous and intermittent RRT [16-21].

Finally, data on the long-term impact of AKI and RRT were not recorded in the database, and concomitant measures likely to prevent or positively influence the course of renal dysfunction (optimization of hemodynamics and renal perfusion, avoidance of nephrotoxic 
drugs) were not analyzed. These issues deserve future prospective evaluations.

\section{Conclusions}

Together with those of Elseviers et al. [22], our findings raise concern about the actual efficacy of RRT. Of course, these results must be cautiously interpreted since the assessment of RRT efficacy through observational data is very challenging. However, they emphasize the need for a critical reappraisal of current RRT practices. Large randomized controlled trials comparing RRT to conservative management in selected ICU patients with AKI, and focusing on RRT timing, are urgently warranted to provide definite conclusions.

\section{Key messages}

- Aside from life-threatening conditions, evidence supporting the use of renal replacement therapy (RRT) in critically ill patients with acute kidney injury (AKI) is lacking. Currently available data on RRT efficacy exclusively stem from observational studies, whose results may have been confounded by treatment selection bias and differences in patients' severity.

- In this study, we extensively dealt with confounding by using the propensity score technique and multivariate regression models to provide an as accurate as possible estimation of RRT efficacy.

- RRT was not associated with decreased mortality and even seemed to impair patients' outcome when initiated too late.

- These results emphasize the need for further randomized studies comparing RRT to conservative management in selected ICU patients, with special focus on RRT timing.

\section{Additional material}

Additional file 1: Baseline characteristics of RIFLE R class patients with and without renal replacement therapy (RRT).

Additional file 2: Baseline characteristics of RIFLE I class patients with and without renal replacement therapy (RRT).

Additional file 3: Baseline characteristics of RIFLE F class patients with and without renal replacement therapy (RRT).

Additional file 4: Lengths of ICU stay after reaching maximum RIFLE class in patients with and without renal replacement therapy (RRT).

Additional file 5: Lengths of ICU stay after reaching maximum RIFLE class in nonsurvivors with and without renal replacement therapy (RRT).

Additional file 6: Association of renal replacement therapy (RRT) with hospital mortality in multivariate conditional logistic regression according to timing of RRT and maximum RIFLE class reached during the ICU stay (model 1 ).

Additional file 7: Association of renal replacement therapy (RRT) with hospital mortality in multivariate conditional logistic regression according to timing of RRT and maximum RIFLE class reached during the ICU stay (model 2).

Additional file 8: Association of renal replacement therapy (RRT) with hospital mortality in multivariate conditional logistic regression (matched patients) according to timing of RRT: results of sensitivity analyses including only patients with a normal serum creatinine value measured on ICU admission.

\section{Abbreviations}

AKI: acute kidney injury; APACHE: Acute Physiology and Chronic Health Evaluation; CKD: chronic kidney disease; Cl: confidence interval; GFR: glomerular filtration rate; ICU: intensive care unit; MDRD: Modification of Diet in Renal Disease; OR: odds ratio; RIFLE: Risk: Injury: Failure: Loss and Endstage renal failure; RRT: renal replacement therapy; SAPS: Simplified Acute Physiology Score; SOFA: Sequential Organ Failure Assessment.

\section{Acknowledgements}

We are indebted in the persons listed below for their participation in the Outcomerea study group:

Scientific committee

Jean-François Timsit (Hôpital Albert Michallon and INSERM U823, Grenoble, France), Elie Azoulay (Medical ICU, Hôpital Saint Louis, Paris, France), Yves Cohen (ICU, Hôpital Avicenne, Bobigny, France), Maïté Garrouste-Orgeas (ICU Hôpital Saint-Joseph, Paris, France), Lilia Soufir (ICU, Hôpital Saint-Joseph, Paris, France), Jean-Ralph Zahar (Microbiology Department, Hôpital Necker, Paris, France), Christophe Adrie (ICU, Hôpital Delafontaine, Saint Denis, France), and Christophe Clec'h (ICU, Hôpital Avicenne, Bobigny, and INSERM U823, Grenoble, France).

Biostatistical and informatics expertise

Jean-Francois Timsit (Hôpital Albert Michallon and INSERM U823, Grenoble, France), Sylvie Chevret (Medical Computer Sciences and Biostatistics Department, Hôpital Saint-Louis, Paris, France), Corinne Alberti (Medical Computer Sciences and Biostatistics Department, Robert Debré, Paris, France), Adrien Français (INSERM U823, Grenoble, France), Aurélien Vesin INSERM U823, Grenoble, France), Christophe Clec'h (ICU, Hôpital Avicenne, Bobigny, and INSERM U823, Grenoble, France), Frederik Lecorre (Supelec, France), and Didier Nakache (Conservatoire National des Arts et Métiers, Paris, France).

Investigators of the Outcomerea database

Christophe Adrie (ICU, Hôpital Delafontaine, Saint Denis, France), Bernard Allaouchiche (ICU, Edouard Herriot Hospital, Lyon), Caroline Bornstain (ICU, Hôpital de Montfermeil, France), Alexandre Boyer (ICU, Hôpital Pellegrin, Bordeaux, France), Antoine Caubel (ICU, Hôpital Saint-Joseph, Paris, France), Christine Cheval (SICU, Hôpital Saint-Joseph, Paris, France), Marie-Alliette Costa de Beauregard (Nephrology, Hôpital Tenon, Paris, France), Jean-Pierre Colin (ICU, Hôpital de Dourdan, Dourdan, France), Mickael Darmon (ICU, CHU Saint Etienne), Anne-Sylvie Dumenil (Hôpital Antoine Béclère, Clamart France), Adrien Descorps-Declere (Hôpital Antoine Béclère, Clamart France), Jean-Philippe Fosse (ICU, Hôpital Avicenne, Bobigny, France), Samir Jamali (ICU, Hôpital de Dourdan, Dourdan, France), Hatem Khallel (ICU, Cayenne General Hospital), Christian Laplace (ICU, Hôpital Kremlin-Bicêtre, Bicêtre, France), Alexandre Lauttrette (ICU, CHU G Montpied, Clermont-Ferrand), Thierry Lazard (ICU, Hôpital de la Croix Saint-Simon, Paris, France), Eric Le Miere (ICU, Hôpital Louis Mourier, Colombes, France), Laurent Montesino (ICU, Hôpital Bichat, Paris, France), Bruno Mourvillier (ICU, Hôpital Bichat, France), Benoît Misset (ICU, Hôpital Saint-Joseph, Paris, France), Delphine Moreau (ICU, Hôpital Saint-Louis, Paris, France), Etienne Pigné (ICU, Hôpital Louis Mourier, Colombes, France), Bertrand Souweine (ICU, CHU G Montpied, Clermont-Ferrand), Carole Schwebel (CHU A Michallon, Grenoble, France), Gilles Troché (Hôpital Antoine, Béclère, Clamart France), Marie Thuong (ICU, Hôpital Delafontaine, Saint Denis, France), Guillaume Thierry (ICU, Hôpital Saint-Louis, Paris, France), Dany Toledano (CH Gonnesse, France), and Eric Vantalon (SICU, Hôpital Saint-Joseph, Paris, France).

Study monitors: Caroline Tournegros, Loic Ferrand, Nadira Kaddour, Boris Berthe, Samir Bekkhouche, Sylvain Anselme. 


\section{Author details}

'Medical-surgical ICU, Avicenne Teaching Hospital, 125 route de Stalingrad, Bobigny, 93000, France. ${ }^{2}$ Albert Bonniot Institute, INSERM U823, University Grenoble 1, rond-point de la Chantourne, La Tronche, 38700, France. ${ }^{3}$ Medical ICU, Saint-Etienne Teaching Hospital, avenue Albert Raimond, SaintPriest-en-Jarez, 42270, France. ${ }^{4}$ Medical ICU, Gabriel Montpied Teaching Hospital, 58 boulevard Montalembert, Clermont-Ferrand, 63003, France. ${ }^{5}$ Saint-Louis Teaching Hospital, 1 avenue Claude-Vellefaux, Paris, 75010, France. ${ }^{6}$ Medical ICU, Albert Michallon Teaching Hospital, boulevard de la Chantourne, La Tronche, 38700, France. ${ }^{7}$ Medical-surgical ICU, Antoine Béclère Teaching Hospital, 157 rue de la Porte de Trivaux, Clamart, 92140, France. ${ }^{8}$ Medical-surgical ICU, Saint-Joseph Hospital, 185 rue Raymond Losserand, Paris, 75014, France. ${ }^{9}$ Medical-surgical ICU, Gonesse Hospital, 25 rue Bernard Février, Gonesse, 95500, France.

\section{Authors' contributions}

CC designed the study and wrote the manuscript; CC and JFT performed the statistical analyses; MD, AL, FC, EA, CS, ASD, MGO, DGT, and YC participated in the collection of data and critically revised the manuscript for important intellectual content. All authors read and approved the final manuscript.

\section{Competing interests}

The authors declare that they have no competing interests.

Received: 12 September 2012 Revised: 28 November 2012

Accepted: 14 December 2012 Published: 19 December 2012

\section{References}

1. Brivet FG, Kleinknecht DJ, Loirat P, Landais PJ: Acute renal failure in intensive care units-causes, outcome, and prognostic factors of hospital mortality; a prospective, multicenter study. French Study Group on Acute Renal Failure. Crit Care Med 1996, 24:192-198.

2. Liano F, Junco E, Pascual J, Madero R, Verde E: The spectrum of acute renal failure in the intensive care unit compared with that seen in other settings. The Madrid Acute Renal Failure Study Group. Kidney Int Suppl 1998, 66:S16-24.

3. Mehta RL, Pascual MT, Gruta CG, Zhuang S, Chertow GM: Refining predictive models in critically ill patients with acute renal failure. $J \mathrm{Am}$ Soc Nephrol 2002, 13:1350-1357.

4. Mehta RL, Pascual MT, Soroko S, Savage BR, Himmelfarb J, Ikizler TA, Paganini EP, Chertow GM: Spectrum of acute renal failure in the intensive care unit: the PICARD experience. Kidney Int 2004, 66:1613-1621.

5. Metnitz PG, Krenn CG, Steltzer H, Lang T, Ploder J, Lenz K, Le Gall JR, Druml W: Effect of acute renal failure requiring renal replacement therapy on outcome in critically ill patients. Crit Care Med 2002, 30:2051-2058.

6. Greenland S, Neutra R: Control of confounding in the assessment of medical technology. Int J Epidemiol 1980, 9:361-367.

7. Brochard L, Abroug F, Brenner M, Broccard AF, Danner RL, Ferrer M, Laghi F, Magder S, Papazian L, Pelosi P, Polderman KH: An Official ATS/ERS/ESICM/ SCCM/SRLF Statement: Prevention and Management of Acute Renal Failure in the ICU Patient: an international consensus conference in intensive care medicine. Am J Respir Crit Care Med 2010, 181:1128-1155.

8. Rosenbaum PR, Rubin DB: The central role of the propensity score in observational studies for causal effects. Biometrika 1983, 70:41-55.

9. Rosenbaum PR, Rubin DB: Reducing bias in observational studies using subclassification on the propensity score. J Am Stat Assoc 1984, 79:516-524.

10. Clec'h C, Alberti C, Vincent F, Garrouste-Orgeas M, de Lassence A, Toledano D, Azoulay E, Adrie C, Jamali S, Zaccaria I, Cohen Y, Timsit JF: Tracheostomy does not improve the outcome of patients requiring prolonged mechanical ventilation: a propensity analysis. Crit Care Med 2007, 35:132-138.

11. Bellomo R, Ronco C, Kellum JA, Mehta RL, Palevsky P: Acute renal failure definition, outcome measures, animal models, fluid therapy and information technology needs: the Second International Consensus Conference of the Acute Dialysis Quality Initiative (ADQI) Group. Crit Care 2004, 8:R204-212.
12. Joffe MM, Rosenbaum PR: Invited commentary: propensity scores. Am J Epidemiol 1999, 150:327-333.

13. Brookhart MA, Schneeweiss S, Rothman KJ, Glynn RJ, Avorn J, Sturmer T: Variable selection for propensity score models. Am J Epidemiol 2006, 163:1149-1156.

14. Rubin $\mathrm{DB}$, Thomas $\mathrm{N}$ : Matching using estimated propensity scores: relating theory to practice. Biometrics 1996, 52:249-264.

15. Outcomerea. [http://outcomerea.org/Macros-SAS/Noir-categorie.html].

16. Augustine JJ, Sandy D, Seifert TH, Paganini EP: A randomized controlled trial comparing intermittent with continuous dialysis in patients with ARF. Am J Kidney Dis 2004, 44:1000-1007.

17. Bellomo R, Cass A, Cole L, Finfer S, Gallagher M, Lo S, McArthur C, McGuinness S, Myburgh J, Norton R, Scheinkestel C, Su S: Intensity of continuous renal-replacement therapy in critically ill patients. $N$ Engl J Med 2009, 361:1627-1638.

18. Mehta RL, McDonald B, Gabbai FB, Pahl M, Pascual MT, Farkas A, Kaplan RM: A randomized clinical trial of continuous versus intermittent dialysis for acute renal failure. Kidney Int 2001, 60:1154-1163.

19. Palevsky PM, Zhang JH, O'Connor TZ, Chertow GM, Crowley ST, Choudhury D, Finkel K, Kellum JA, Paganini E, Schein RM, Smith MW, Swanson KM, Thompson BT, Vijayan A, Watnick S, Star RA, Peduzzi P: Intensity of renal support in critically ill patients with acute kidney injury. N Engl J Med 2008, 359:7-20.

20. Schiffl H, Lang SM, Fischer R: Daily hemodialysis and the outcome of acute renal failure. N Engl J Med 2002, 346:305-310.

21. Vinsonneau C, Camus C, Combes A, Costa de Beauregard MA, Klouche K, Boulain T, Pallot JL, Chiche JD, Taupin P, Landais P, Dhainaut JF: Continuous venovenous haemodiafiltration versus intermittent haemodialysis for acute renal failure in patients with multiple-organ dysfunction syndrome: a multicentre randomised trial. Lancet 2006, 368:379-385.

22. Elseviers MM, Lins RL, Van der Niepen P, Hoste E, Malbrain ML, Damas P, Devriendt J, SHARF investigators: Renal replacement therapy is an independent risk factor for mortality in critically ill patients with acute kidney injury. Crit Care 2010, 14:R221.

23. Ahlstrom A, Tallgren M, Peltonen S, Pettila V: Evolution and predictive power of serum cystatin C in acute renal failure. Clin Nephrol 2004, 62:344-350.

24. Delanaye P, Lambermont B, Chapelle JP, Gielen J, Gerard P, Rorive G: Plasmatic cystatin $\mathrm{C}$ for the estimation of glomerular filtration rate in intensive care units. Intensive Care Med 2004, 30:980-983.

25. Herget-Rosenthal S, Marggraf G, Husing J, Goring F, Pietruck F, Janssen O, Philipp T, Kribben A: Early detection of acute renal failure by serum cystatin C. Kidney Int 2004, 66:1115-1122.

26. Mishra J, Dent C, Tarabishi R, Mitsnefes MM, Ma Q, Kelly C, Ruff SM, Zahedi K, Shao M, Bean J, Mori K, Barasch J, Devarajan P: Neutrophil gelatinase-associated lipocalin (NGAL) as a biomarker for acute renal injury after cardiac surgery. Lancet 2005, 365:1231-1238.

27. Nickolas TL, O'Rourke MJ, Yang J, Sise ME, Canetta PA, Barasch N, Buchen C, Khan F, Mori K, Giglio J, Devarajan P, Barasch J: Sensitivity and specificity of a single emergency department measurement of urinary neutrophil gelatinase-associated lipocalin for diagnosing acute kidney injury. Ann Intern Med 2008, 148:810-819.

28. Villa P, Jimenez M, Soriano MC, Manzanares J, Casasnovas P: Serum cystatin C concentration as a marker of acute renal dysfunction in critically ill patients. Crit Care 2005, 9:R139-143

29. Wagener G, Jan M, Kim M, Mori K, Barasch JM, Sladen RN, Lee HT: Association between increases in urinary neutrophil gelatinaseassociated lipocalin and acute renal dysfunction after adult cardiac surgery. Anesthesiology 2006, 105:485-491.

30. Zappitelli M, Washburn KK, Arikan AA, Loftis L, Ma Q, Devarajan P, Parikh CR, Goldstein SL: Urine neutrophil gelatinase-associated lipocalin is an early marker of acute kidney injury in critically ill children: a prospective cohort study. Crit Care 2007, 11:R84.

31. Ostermann M, Chang RW: Acute kidney injury in the intensive care unit according to RIFLE. Crit Care Med 2007, 35:1837-1843, quiz 1852.

32. Uchino S, Bellomo R, Goldsmith D, Bates S, Ronco C: An assessment of the RIFLE criteria for acute renal failure in hospitalized patients. Crit Care Med 2006, 34:1913-1917. 
33. Hoste EA, Clermont G, Kersten A, Venkataraman R, Angus DC, De

Bacquer D, Kellum JA: RIFLE criteria for acute kidney injury are associated with hospital mortality in critically ill patients: a cohort analysis. Crit Care 2006, 10:R73.

34. Hoste EA, Kellum JA: Acute kidney injury: epidemiology and diagnostic criteria. Curr Opin Crit Care 2006, 12:531-537.

\section{doi:10.1186/cc11905}

Cite this article as: Clec'h et al: Efficacy of renal replacement therapy in critically ill patients: a propensity analysis. Critical Care 2012 16:R236.

Submit your next manuscript to BioMed Central and take full advantage of:

- Convenient online submission

- Thorough peer review

- No space constraints or color figure charges

- Immediate publication on acceptance

- Inclusion in PubMed, CAS, Scopus and Google Scholar

- Research which is freely available for redistribution

Submit your manuscript at www.biomedcentral.com/submit
C Biomed Central 